\title{
Segurança e insegurança em Salvador: O que revelam os indicadores de segurança pública?
}

\author{
Tânia Benevides', Aline Pauliana Lima1, Tássio Silva², Jéssica \\ Oliveira $^{3}$, Maurício Freire ${ }^{4}$ e Victor Said ${ }^{5}$
}

\author{
${ }^{1}$ Departamento de Ciências Humanas da Universidade do Estado da Bahia (UNEB), Brasil \\ tbenevides@uneb.br; paulianasf87@gmail.com | http://orcid.org/0000-0001-9191-7831; \\ https://orcid.org/0000-0002-0129-5950 \\ ${ }^{2}$ Faculdade de Direito da Universidade Federal da Bahia (UFBA), Brasil | \\ tassiosantoss@hotmail.com | https://orcid.org/0000-0003-2507-8704 \\ ${ }^{3}$ Departamento de Educação da Universidade do Estado da Bahia (UNEB), Brasil | \\ jenoliveira@uneb.br | https://orcid.org/0000-0001-8542-9364 \\ ${ }^{4}$ Escola de Administração da Universidade Federal da Bahia (UFBA), Brasil \\ mauriciosmith.ufba@gmail.com | https://orcid.org/0000-0002-1245-2632 \\ ${ }^{5}$ Departamento de Ciências Humanas da Universidade do Estado da Bahia, Brasil | \\ 231610248@uneb.br | https://orcid.org/0000-0002-4761-5227
}

Resumo: Esse artigo avalia os indicadores de segurança pública, buscando compreender o que revelam os dados dos Crimes Violentos Letais Intencionais (CVLI) e dos Crimes Violentos contra o Patrimônio (CVP) compilados pela Secretaria de Segurança Pública do Estado da Bahia (SSP-BA), entre os anos de 2017 e 2019. O estudo parte da seguinte questão de investigação: o que os indicadores de segurança pública CVLI e CVP revelam sobre a cidade de Salvador? O objetivo geral desse artigo é caracterizar a segurança ou insegurança na cidade de Salvador a partir destes dois indicadores. Para tanto, foi realizada uma pesquisa descritiva de abordagem qualitativa, a partir da pesquisa de campo do Projeto Qualidade do Ambiente Urbano de Salvador (QUALISalvador) em 2019, e baseada na pesquisa documental circunscrita pelo relatório de dados sobre os registros de criminalidade cedidos pela SSP-BA no período supracitado. A análise de dados secundários não buscou generalizações, centrando na análise da cidade de Salvador, respeitando as especificidades locais e deu-se através das seguintes etapas: leitura dos dados coletados; categorização dos dados em unidades menores - entre os anos de 2017 a 2019 e pelo agrupamento dos indicadores CVP e CVLI; análise através de comparação para refinamento - com a definição das categorias e identificação de padrões; além do confronto entre os dados coletados no documento e as categorias analíticas do referencial teórico. Verificou-se que o número de homicídios em Salvador é muito grande, o que corrobora com os dados secundários publicados pelo Atlas da Violência de 2019, que revelaram Salvador como a quinta capital mais violenta do Brasil.

Palavras-chave: Segurança; Segurança Pública; Indicadores de Segurança; Salvador; QUALISalvador.

\section{Security and Insecurity in Salvador: What do Public Security Indicators Reveal?}

\begin{abstract}
This article evaluated the public security indicators, seeking to understand what the data from Intentional Lethal Violent Crimes (CVLI) and Violent Crimes against Heritage (CVP) reveal, compiled by the State of Bahia Public Security Secretariat (SSP-BA), between the years 2017 and 2019. The study starts from the following research question: what do the public security indicators CVLI and CVP reveal about the city of Salvador? The general objective of this article is to characterize security or insecurity in the city of Salvador from these two indicators. To this end, a descriptive research with a qualitative approach was carried out, based on the field research of the Quality Project of the Urban Environment of Salvador (QUALISalvador) in 2019, and based on the documentary research circumscribed by the data report on the crime records provided by the SSP -BA in the aforementioned period. An analysis of secondary data did not seek generalizations, focusing on the analysis of the city of Salvador, respecting local specificities and took place through the following steps: reading of the collected data; categorization of data into smaller units - between the years 2017 to 2019 and by grouping the CVP and CVLI indicators; analysis through comparison for refinement - with the definition of categories and identification of patterns; in addition to the confrontation between the data collected in the document and as analytical categories of the theoretical framework. It was found that the number of homicides in Salvador is very large, which corroborates the secondary data published by the 2019 Atlas of Violence, which revealed Salvador as the fifth most violent capital in Brazil.
\end{abstract}

Keywords: Security; Public Security; Security Indicators; Salvador; QUALISalvador. 


\section{Introdução}

A cidade, tal como destacam Gledhill et al. (2017), é um ente complexo e contraditório. Essa condição pode ser explicitada pelo fato de ela ser uma utopia para uns e uma distopia para outros. No contexto urbano, ao tratar da temática segurança, a contradição ganha destaque, pois as cidades apresentam problemas de segurança muito estruturais, os quais são potencializados pela interseção de um conjunto de fatores, a saber: a precarização do trabalho, a concentração de renda e riquezas, o agravamento das desigualdades sociais, o racismo estrutural, a discriminação de gênero, as políticas e práticas de segurança pública, entre outros. Todos esses fatores se entrecruzam no espaço urbano, demandando cuidadosa análise dessa categoria a fim de compreender o seu impacto na qualidade do ambiente intraurbano de Salvador.

Para entender a segurança e a insegurança em Salvador, é preciso analisar os resultados dos indicadores de segurança pública, explicitando como se expressam e o que revelam. Isto posto, este artigo foi formulado a partir da seguinte questão de investigação: o que os indicadores de segurança pública de Crimes Violentos Letais e Intencionais (CVLI) e de Crimes Violentos contra o Patrimônio (CVP) revelam sobre a cidade de Salvador? O objetivo geral desse estudo é caracterizar a segurança ou a insegurança na cidade de Salvador, a partir dos indicadores CVP e CVLI. Para isso, foram definidos os seguintes objetivos específicos: Identificar o número de homicídios entre 2017 e 2019, com especial ênfase no ano de 2019, ano base do estudo de campo realizado pelo Projeto Qualidade do Ambiente Urbano de Salvador (QUALISalvador), explicitando os marcadores sociais apresentados no indicador CVLI, dada a sua relevância; e identificar a influência do CVP no contexto urbano.

A reflexão desenvolvida teve como referência dados secundários fornecidos pela Secretaria de Segurança Pública do Estado da Bahia (SSP-BA, 2020), extraídos da base de dados que registra os crimes ocorridos na cidade de Salvador, abarcando o período de 01 de janeiro de 2017 a 31 de dezembro de 2019. Tais dados foram utilizados para mensurar e compor os indicadores de segurança pública - CVLI e CVP.

Este artigo está dividido em seis seções, a primeira aqui apresentada é a introdução; a segunda seção apresenta um sintético delineamento do campo da segurança pública no Brasil; a metodologia utilizada no presente estudo está apresentada na terceira seção; a quarta seção é destinada a análise dos dados secundários trabalhados com os principais autores do campo da segurança pública e da segurança urbana; a quinta sessão que traz as considerações finais sobre o percurso e resultados encontrados, de modo à responder a questão investigada e, por fim, a sexta e última sessão apresenta as referências utilizadas pelos autores.

\section{A Segurança Pública no Brasil e seus Indicadores}

A segurança pública é um tema vasto e complexo sobre o qual todos possuem um ponto de vista. Isso ocorre em função do excesso de notícias, conversas e opiniões, transmitindo a impressão de que todos falam da mesma coisa e concordam quanto ao essencial. É comum nos depararmos com a dificuldade de compreensão das causas, dimensões e consequências do que, genericamente, qualificamos como violência e segurança (Costa \& Lima, 2014; Soares, 2019).

Na busca pela construção de um conceito de segurança, Soares (2019) apresenta uma série de inquietações que levam a algumas conclusões sobre a segurança pública, a saber:

1) Não se reduz à existência nem à inexistência de crimes; 2) não se esgota na presença nem na ausência de fatos visíveis e quantificáveis, embora tenha relação com a experiência emocional, física e/ou simbólica da violência intolerável; 3) incorpora a dimensão subjetiva, como o medo, que é sempre intersubjetivo, porque experimentado em sociedade; 
4) é indissociável de algumas dimensões políticas fundamentais, como democracia ou ditadura, e da regência de formas locais (ou capilares e domésticas) de poder, tirânicas ou libertárias; 5) diz respeito a toda a coletividade; 6) [...] envolve as esferas pública e privada; 7) não pode ser definida por um critério fixo e permanente nem mensurada de forma abstrata e artificial; 8) depende de contextos específicos e de histórias singulares ... (p. 119).

Nesse sentido, a segurança pública é social, histórica e culturalmente relativa, mesmo que se considere que essa relatividade esteja limitada pelos balizamentos substantivos - a violência, o regime político e as formas de poder local ou capilar. Segurança pública é "... a estabilização universalizada, no âmbito de uma sociedade em que vigora o Estado democrático de direito, de expectativas positivas a respeito das interações sociais, ou da sociabilidade, em todas as esferas da experiência individual" (Soares, 2019, p. 119).

Para além do conceito, a segurança pública é um campo empírico e organizacional que estrutura e direciona instituições e relações sociais em torno da forma como o Estado regula e administra a ordem e o conflito (Costa \& Lima, 2014).

Os estudos sobre segurança e, em especial, segurança pública, são diversos e advêm de variados campos de estudos. No Brasil, o debate sobre segurança pública deslocou o seu foco do sistema legal para o desenvolvimento e implementação de políticas públicas, conforme demonstra linha do tempo publicada pelo Ministério da Segurança Pública (2018) a seguir (Fig. 1):

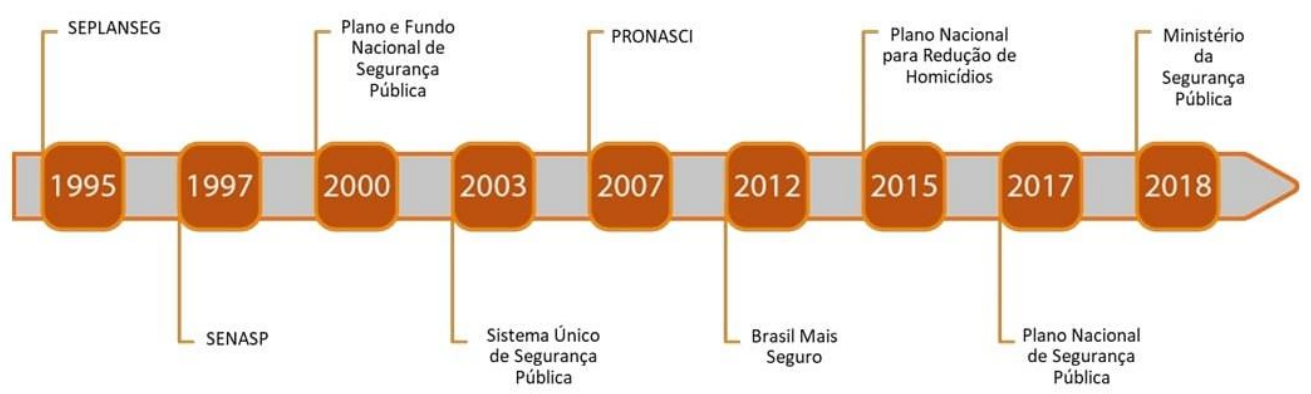

Fig. 1. Linha do tempo das principais iniciativas do Governo Federal em segurança pública entre os ano de 1995 e 2018, no Brasil.

Ao longo deste intervalo temporal de 1995 a 2018, alternativas para os modelos de ações e gestão de segurança pública foram concebidos de forma que cada unidade membro da federação (governos estaduais) passou a responder por sua política de segurança, e o presidente (Governo Federal) a responder pela política de segurança do país - perante outras nações e órgãos internacionais. Com as normas jurídicas estabelecidas para acesso ao Fundo Nacional de Segurança Pública - criado a partir da Medida Provisória $n^{\circ}$ 2.029/00 -, fincou-se o objetivo de apoiar projetos na área de segurança pública e prevenção à violência em alinhamento com a aceitação por parte de cada estado do Sistema Único de Segurança Pública (SUSP; Dias, 2010).

O poder federal assumiu então o papel, sobretudo, de incentivar, por meio de financiamentos, intervenções nos estados que atendam a certos requisitos técnicos e políticos. A segurança pública é, então, fundamentalmente, de competência dos estados. Dessa forma, cada estado possui as suas forças policiais - polícia civil e polícia militar - e seu tribunal de justiça, alinhando-se ao modelo federativo, e a esfera municipal tem papel principalmente na área da prevenção (Cano, 2006).

Em paralelo, no campo da segurança, foram estabelecidos indicadores mensuráveis de criminalidade, a saber: categoria CVLI (Homicídio doloso; roubo seguido de morte; lesão corporal seguida de morte; e feminicídio); categoria CVP (Extorsão mediante sequestro; 
roubo a estabelecimento comercial; roubo a residência; roubo a transeunte; roubo a veículo; roubo a ônibus; entre outros).

\section{Metodologia}

Este artigo se constitui como um recorte de uma pesquisa mais ampla desenvolvida por pesquisadores vinculados ao Projeto Qualidade do Ambiente Urbano de Salvador (QUALISalvador). A pesquisa maior tem por objetivo produzir e difundir conhecimento sobre a realidade urbano-ambiental da cidade do Salvador, na escala intraurbana, por bacia hidrográfica e por bairro, tendo como referência o Índice de Qualidade UrbanoAmbiental de Salvador - IQUALISalvador. O recorte mencionado resulta de parte do trabalho dos pesquisadores que avaliam a segurança pública e a sua influência no IQUALISalvador.

Para sua realização inicialmente partiu-se de uma pesquisa bibliográfica buscando sustentação teórica no campo da segurança pública. Foram consultados diversos autores, entretanto, para a sustentação dos conceitos os autores que mais se alinharam foram: Haesbaert (2018), Buzan (2012) e Soares (2019, 2021a, 2021b). Esses autores apresentam, de formas diferentes, mas muito convergentes, um debate em torno da segurança, mostrando quão ampla e multifacetada pode ser a conceituação do tema.

Minayo (2011) adverte que um levantamento bibliográfico bem feito permite, a partir do conhecimento já produzido, trabalhar bem os conceitos, viabilizando e sustentando as demais etapas da pesquisa. Foi nessa fase que os sujeitos/objetos de investigação foram construídos teoricamente, possibilitando uma relação de intersubjetividade e de interação social, que se constitui em um trabalho compreensivo, que apesar de não ser uma realidade concreta é uma descoberta constituída por todas as disposições, que são: elementos delineadores da pesquisa, quadro conceitual e metodológico e dados secundários coletados.

Definida a base teórica, fez-se necessária a busca por dados secundários que sustentassem a análise, visto que era preciso levantar o número de homicídios e demais crimes, registrados pela Secretaria de Segurança Pública (2020) que caracterizassem os indicadores definidos pelo Sistema Único de Segurança Pública (SUSP; Ministério de Segurança Pública, 2018), que são Crimes Violentos Letais Intencionais (CVLI) e Crimes Violentos contra o Patrimônio (CVP). Na oportunidade, foi cedido pela SSP-BA (2020) o relatório de "Registro de ocorrências policiais no município de Salvador - período de 01 de janeiro de 2017 a 31 de dezembro de 2019". Os dados apresentados nesse trabalho se constituem como dados secundários extraídos do relatório em referência, com o recorte temporal de 2019, ano base do estudo, sendo os dados quanto a temporalidade, transversal. Trata-se, portanto, de uma pesquisa documental (Appolinário, 2012).

Esse artigo constitui-se como descritivo no que concerne a profundidade, pois descreve uma realidade sem nela interferir, não estabelecendo relação de causalidade; é documental no que se refere a origem dos dados, pois utiliza dados provenientes de fonte documental; e é um estudo de abordagem qualitativa, pois lida com um fenômeno prevendo a análise hermenêutica dos dados coletados.

A análise de dados secundários, por ser uma pesquisa de abordagem qualitativa que não buscou generalizações, centrando na análise dos dados sobre a cidade de Salvador, a qual deu-se através das seguintes etapas: leitura dos dados coletados; categorização dos dados em unidades menores - entre os anos de 2017 a 2019 e pelo agrupamento dos indicadores CVP e CVLI; análise através de comparação para refinamento - com a definição das categorias e identificação de padrões, como idade, sexo, etnia, entre outros: além do confronto entre os dados coletados no documento e as categorias analíticas do referencial teórico (Appolinário, 2012; Minayo, 2011). 


\title{
4. Impressões e Expressões da Segurança e da Violência: o que Revelam os Indicadores de Segurança Pública sobre a Cidade de Salvador?
}

\begin{abstract}
Salvador, assim como muitas cidades latino-americanas, é marcada pelos traços apresentados por Harvey (2014), a saber: aprofundamento do processo de neoliberalização; transformação do mundo do trabalho; legitimação de novos processos de acumulação e precarização; potencialização da cidade como espaço da produção e reprodução do capital; redução de investimentos públicos; aprofundamento da segregação socioespacial; ampliação da escala da degradação do patrimônio ambiental; captura do Estado, da política pública e do planejamento por blocos políticos e econômicos vinculados a interesses especulativos; e recuos das energias utópicas. Tais traços afetam negativamente as dimensões econômica, social, ambiental e política, ampliando as desigualdades e a concentração da riqueza socialmente produzida. As lógicas econômicas e políticas que hierarquizam os espaços urbanos levam à mercantilização das cidades. Nos centros urbanos, inclusive em Salvador, as experiências enraizadas na vida cotidiana são sobrepostas pelos valores e conteúdos hegemônicos, tornando a cidade um instrumento de acumulação de recursos e de poder. No espaço urbano, o poder é concentrado e é estruturado hierarquicamente de acordo com o acesso a bens e riquezas.
\end{abstract}

Há no contexto urbano uma heterogeneidade de espaços e comportamentos que se expressam de forma violenta, afetando a impressão que a população tem sobre a segurança ou a insegurança no seu contexto. Haesbaert (2018), Buzan (2012) e Soares $(2019,2021 a, 2021 b)$ apresentam debates sobre segurança e segurança pública, demostrando a polissemia de conceitos.

Para Haesbaert, a segurança deve ser focalizada em sentido amplo, já que diz respeito à garantia da vida e envolve os riscos e a violência. Nessa visão os indivíduos buscam a "segurança" de continuar vivendo. Para Buzan, a segurança pode ser analisada a partir de quatro perspectivas: tipologia de segurança; ameaças; uso da força e discurso do Estado. Por fim, Soares aborda a segurança demonstrando que pode derivar da sensação de insegurança causada por acidentes naturais, crises econômicas, dramas familiares, violências e epidemias. $\mathrm{O}$ autor aponta a segurança como uma experiência múltipla e polissêmica que engloba uma pluralidade de esferas da vida coletiva.

Ao tratar da temática segurança e insegurança, trata-se também de temáticas como vida e morte. Ao delimitar essa análise para a segurança pública no contexto urbano de Salvador, verifica-se que essa é uma cidade violenta e, portanto, insegura. Para assegurar essa afirmação é necessário refletir sobre os números, suas causas e como a população acostuma-se a conviver com essa realidade (Soares, 2021a).

Segundo dados da SSP-BA (2020), apresentados na tabela 1, destaca-se que entre os crimes do indicador CVLI, o número de homicídios dolosos intencionais em Salvador, entre 2017 e 2019, sofreu redução de $26,92 \%$, entretanto, esse indicador ainda permanece alto se comparado a variação de outras capitais brasileiras no período de 2016 a 2017 (Cerqueira et al., 2019). Em relação ao CVP, foram registradas 93.956 ocorrências no período de 2017 a 2019 (Secretaria de Segurança Pública, 2020). 
Tabela 1. Taxas de CVLI - total e recortes de Homicídios Dolosos e por gênero - e CVP total em Salvador, entre 2017 e 2019. Fonte: SSP-BA (2020).

\begin{tabular}{ccccccccc}
\hline \multirow{2}{*}{ Ano } & $\begin{array}{c}\text { CVLI } \\
\text { total }\end{array}$ & $\begin{array}{c}\text { Homicídio } \\
\text { Doloso }\end{array}$ & $\begin{array}{c}\text { Homicídio } \\
\text { Doloso } \\
\text { Masculino }\end{array}$ & $\begin{array}{c}\text { Homicídio } \\
\text { Doloso } \\
\text { Feminino }\end{array}$ & $\begin{array}{c}\text { Homicídio } \\
\text { Doloso não } \\
\text { informado (N/I) }\end{array}$ & $\begin{array}{c}\text { Outros } \\
\text { crimes }\end{array}$ & $\begin{array}{c}\text { CVP } \\
\text { total }\end{array}$ \\
$\mathbf{2 0 1 7}$ & 1445 & 1375 & 1271 & 82 & 22 & 70 & 34102 \\
$\mathbf{2 0 1 8}$ & 1180 & 1144 & 1063 & 63 & 18 & 36 & 32684 \\
$\mathbf{2 0 1 9}$ & 1056 & 1008 & 949 & 57 & 2 & 48 & 27170 \\
Total & $\mathbf{3 6 8 1}$ & $\mathbf{3 5 2 7}$ & $\mathbf{3 2 8 3}$ & $\mathbf{2 0 2}$ & $\mathbf{4 2}$ & $\mathbf{1 5 4}$ & $\mathbf{9 3 9 5 6}$ \\
\hline
\end{tabular}

A base de dados fornecida pela SSP-BA (2020) compreende o intervalo de 2017 a 2019 , entretanto ressalta-se, que em função do recorte temporal da Pesquisa QUALISalvador, para elaboração do mapa (Fig. 2) utilizou-se os dados de 2019, período que coincide com a realização da pesquisa de campo para estruturação do IQUALISalvador, conforme mencionado na metodologia.

Os homicídios dolosos são o maior problema de violência no Brasil, a questão mais candente. Vale ressaltar que a média brasileira, em 2017, é de 41 homicídios dolosos por 100 mil habitantes - termo de comparação utilizado internacionalmente para grandes municípios - (Cerqueira et al., 2019), sendo que neste ano, o Brasil registrou 63.886 homicídios dolosos; aproximadamente 62 mil em 2018; e, até o momento da escrita deste artigo, não foram oficializados os dados do ano de 2019 (Soares, 2021b).

No contexto da cidade de Salvador, a prevalência da violência letal revela as diferenças entre as condições urbanas dos bairros (SSP-BA, 2020). A Fig. 2, apresentada a seguir, revela os bairros com as maiores taxas de homicídios no ano de 2019 - mais de 90 a cada 100 mil habitantes. São eles: Retiro (1.155), Comércio (807), Granjas Rurais Presidente Vargas (466), Cassange (328), Calçada (222), Jardim Santo Inácio (218), Santa Luzia (158), Nova Esperança (155), Baixa de Quintas (153), Campinas de Pirajá (140), Lobato (130), Cajazeiras VII (126), Praia Grande (123), Calabetão (120), Alto da Terezinha (107) e Cajazeiras II (92).

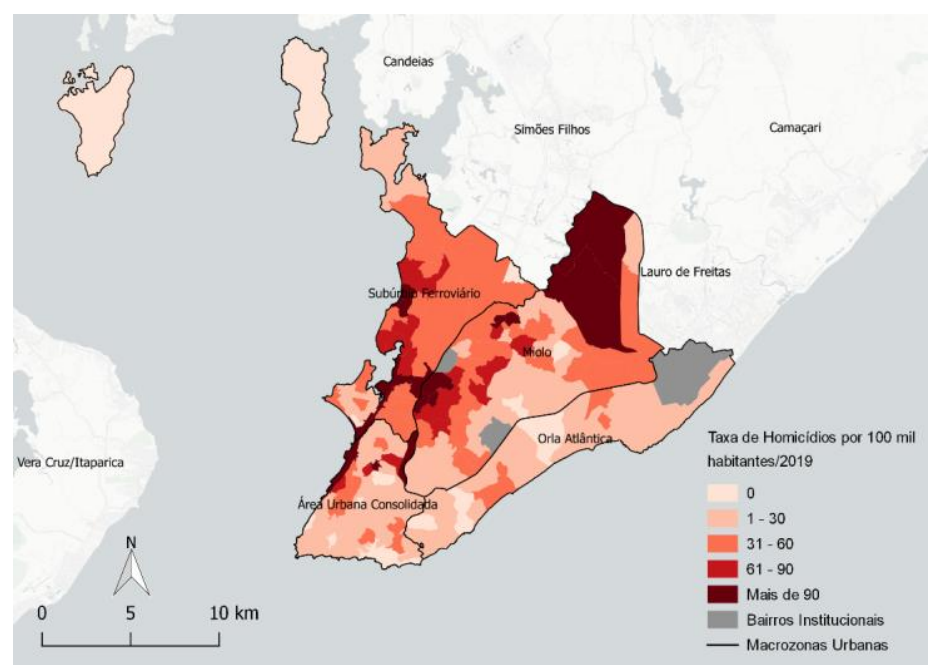

Fig. 2. Taxa de homicídios por 100 mil habitantes em Salvador no ano de 2019. Fonte: elaborada pelos autores com dados da SSP-BA (2020). 
Esses dados revelam que na Cidade de Salvador a violência, como em outros municípios brasileiros, se intensifica nos bairros ditos "periféricos", afetando principalmente os jovens com faixa etária compreendida entre 15 e 29 anos, do sexo masculino, e pretos e pardos na sua maioria (Cerqueira et al., 2019).

Essa caracterização ajuda a entender a negligência, a insensibilidade e a indiferença com a qual a sociedade baiana convive com esses dados, que se referem a uma realidade tão dramática e naturalizada, pois é o "outro". Ajuda também a entender que as políticas e práticas da segurança pública se baseiam em concepções de que há lugares perigosos e criminosos, assim como pessoas também perigosas e criminosas. Essas concepções combinam preconceitos raciais com preconceitos de classe social, mas também envolvem uma série de disputas mais gerais para o controle do espaço urbano em uma cidade neoliberal, convidando à reflexão sobre as lógicas de securitização e função social da polícia (Gledhill et al., 2017).

Considerando essa expressão da violência e da insegurança na cidade de Salvador, como compreender as variáveis ou os fatores que levam a essa configuração? Ao discutir segurança internacional, Buzan (2012) traz ao debate a noção de segurança, demonstrando que está relacionada a temas políticos cruciais, como Estado, autoridade, legitimidade, política e soberania. Para ele, os debates conceituais sobre segurança devem compreender um legado histórico com as suas influências culturais e os debates políticos. Outro aspecto importante revelado na análise é que a segurança é sempre um "conceito hifenizado", pois está sempre vinculado "... a um objeto de referência específico, a localidades internas e externas, a um ou mais setores e a um modo particular de pensar sobre política" (Buzan, 2012, p. 37).

Trazer o "conceito hifenizado" de Buzan (2012) para o centro do debate nos permite pensar nas diferentes noções de segurança, avaliando as que afetam diretamente o contexto urbano, de modo que se faz necessária a reflexão sobre a dimensão teórica e prática que gira em torno dela.

Em Salvador, a insegurança e a violência, segundo Cerqueira et al. (2019), vinculam-se ao tráfico de drogas, mas também ganham contorno na adoção de uma linha mais reativa por parte da força policial, o que alimenta o ciclo de violência. Nesse posicionamento, configura-se uma polarização entre o crime e a segurança pública, afetando as impressões da insegurança e da violência na cidade de Salvador.

A violência e a insegurança nessa cidade, como em qualquer outra, não se resolvem atribuindo a problemática a grupos minoritários, aos pobres ou aos marginalizados. A responsabilidade pelos perigos urbanos tem variações enormes no nível de civilidade e de segurança entre grupos e entre as zonas urbanas. Há problemas e impactos complexos na criminalidade e na violência, em qualquer escala: intraurbana e metropolitana (Jacobs, 2011).

Ainda que o desenvolvimento urbano desigual seja de fato um fator que fomenta e amplia o conflito social e ainda que a percepção da violência ganhe diferentes contornos em diferentes contextos urbanos, Harvey (2014) chama a atenção para o fato de que as cidades nunca foram lugares harmoniosos, sem confusão, conflito ou violência. A sensação de insegurança na cidade é, principalmente, fruto do desequilíbrio estrutural imposto pelo modo de produção vigente.

\section{Considerações Finais}

No contexto da cidade de Salvador, a prevalência da violência letal, revelada no Mapa apresentado (Fig. 2), centra-se nos bairros ditos periféricos, ocorrências que acirram as diferenças entre as condições urbanas dos bairros. 
Nos bairros chamados nobres, onde mora a "classe média e alta", o patrulhamento, a segurança privada e as placas ameaçadoras explicitam o foco da defesa da esfera privada, resultante do medo e do estigma em relação ao "outro" - medo principalmente dos crimes violentos contra o patrimônio, que são amplamente noticiados, revelados em estatísticas ou na verbalização de amigos, vizinhos, familiares, entre outros que cercam os moradores da cidade. A violência, o medo e a insegurança, em uma sociedade marcadamente individualista, fragmentada e dividida, levam à valorização da segurança numa perspectiva individual, com uma visão distorcida sobre o que poderia trazer mais segurança para a cidade.

Apesar das diferenças em termos socioeconômicos e de infraestrutura entre bairros, não é o policiamento que será pré-requisito para a segurança. O policiamento é um recurso capaz de trazer segurança para Salvador, mas não é capaz de parar o ciclo vicioso da violência urbana. Essa é uma concepção estreita, como apresenta Cano (2006), ao falar das políticas de segurança pública no Brasil e das tentativas de modernização e democratização. É preciso uma visão mais ampla que entenda o crime e os interesses que fundamentam a securitização da vida urbana.

Assim, os indicadores de segurança pública CVLI e CVP revelam que na cidade de Salvador os homicídios afetam bairros periféricos de forma mais concreta e acirram a insegurança de modo subjetivo. Portanto, pode-se caracterizar a cidade de Salvador como violenta e insegura. Os dados da SSP-BA (2020) ajudam a reforçar esse sentimento do coletivo, evidenciando o número de homicídios em 2019 - 1.008 homicídios dolosos - e o número de ocorrências de CVP - 27.170 em 2019. A percepção de segurança fica então negativamente comprometida.

A cidade deve ser um espaço plural, que comporte os diversos agrupamentos humanos, proporcionando espaço para as mais diferentes manifestações sociais, que também são aspectos de manutenção da segurança (Gehl, 2015; Jacobs, 2011). Nesse contexto, Salvador, como tantas outras cidades, tem sido constituída em um recurso, em objeto per se, de acumulação de capital e de poder. Nesse projeto, o pleno direito à segurança restringe-se sobremaneira.

A estruturação dos espaços urbanos possui papel fundamental na redução da criminalidade, da violência, do medo e da insegurança, pois espaços segregados somados à carência de recursos e serviços, como educação, cultura e lazer proporcionam o aumento dos indicadores de violência e, consequentemente, da insegurança.

\section{Agradecimentos}

Às instituições financiadoras do Projeto QualiSalvador: Fundação de Amparo à Pesquisa do Estado da Bahia (FAPESB) e Empresa Baiana de Águas e Saneamento S.A. (EMBASA), e às instituições: Universidade Federal da Bahia, Universidade do Estado da Bahia e Universidade Estadual de Feira de Santana.

\section{Referências}

Appolinário, F. (2012). Metodologia de ciência: filosofia e prática da pesquisa (2ª ed.). Cengage Learning.

Buzan, B. (2012) A evolução dos estudos de segurança internacional. Editora UNESP.

Cano, I. (2006). Políticas de segurança pública no Brasil: tentativas de modernização e democratização versus a guerra contra o crime. Sur. Revista Internacional de Direitos Humanos, 3(5), 136-155. https://doi.org/10.1590/S1806-64452006000200007

Cerqueira, D., Lima, R. S., Bueno, S., Alves, P. P., Reis, M., Cypriano, O., \& Armstrong, K. (2019). Atlas da violência retratos dos municípios brasileiros - 2019. IPEA. 
Costa, A. T., \& Lima, R. S. (2014) Segurança pública. In R. S. Lima, J. L. Ratton, \& R. G. Azevedo (Orgs.). Crime, polícia e justiça no Brasil. Contexto.

Dias, L. L. (2010). A política de segurança pública entre o monopólio legítimo da força e os direitos humanos: a experiência da Paraíba no pós 1988 [Tese de Doutorado, Universidade Federal de Pernambuco].

Gehl, J. (2015). Cidades para pessoas (3ª ed.). Perspectiva.

Gledhill, J., Hita, M. G., \& Perelman, M. (2017). Introdução a questão urbana, hoje. In J. Gledhill, M. G. Hita \& M. Perelman (Orgs.), Disputas em torno do espaço urbano: processos de [re] produção/construção e apropriação da cidade (pp. 31-46). Edufba.

Haesbaert, R. (2018). Viver no limite: território e multi/transterritorialidade em tempos de insegurança e contenção. Bertrand Brasil.

Harvey, D. (2014). 17 contradições e o fim do capitalismo. Boitempo.

Jacobs, J. (2011). Morte e vida das grandes cidades ( $3^{\mathrm{a}}$ ed.). Martins Fontes.

Minayo, M. C. S. (2011). Trabalho de campo: contexto de observação, interação e descoberta. In S. F. Deslandes, \& M. C. S. Minayo (Org.), Pesquisa social: teoria, método e criatividade (30 a ed., pp. 61-77). Vozes.

Ministério da Segurança Pública (2018). Plano e política nacional de segurança pública e defesa social. SUSP - Sistema Único de Segurança Pública (2018-2028).

Secretaria de Segurança Pública (2020). Registro de ocorrências policiais no município de Salvador. Período de 01 de janeiro de 2017 a 31 de dezembro de 2019. Governo da Bahia.

Soares, L. E. (2019). Desmilitarizar: segurança pública e direitos humanos. Boitempo.

Soares, L. E. (2021a). Violência e segurança pública. Editora PUCRS.

Soares, L. E. (2021b). Violência e segurança pública - parte 1 [Video]. PUCRS.

https://salavirtual.pucrs.br/curso/violencia-e-seguranca-publica/conteudo?item $=23667$ 